\title{
Growth in infancy and bone mass in later life
}

\author{
Cyrus Cooper, Caroline Fall, Peter Egger, Richard Hobbs, Richard Eastell, David Barker
}

\begin{abstract}
Objective-To examine the association between weight in infancy and bone mass during the seventh decade of life in a population based cohort for which detailed birth and childhood records were preserved.

Methods-189 women and 224 men who were aged 63-73 years and were born in East Hertfordshire underwent bone densitometry by dual energy $x$ ray absorptiometry. Measurements were also made of serum osteocalcin and urinary excretion of type 1 collagen cross linked N-telopeptide.

Results-There were statistically significant associations between weight at 1 year and bone mineral content (but not bone mineral density) at the spine $(P<0.02)$ and femoral neck $(P<0.01)$ among women, and spine $(P<0.03)$ among men. Although serum osteocalcin was negatively correlated with bone mineral density at both sites among men and women, infant weight was not significantly associated with either biochemical marker of bone turnover.

Conclusions-These data confirm our previous observations that growth in infancy is associated with skeletal size in adulthood, and suggest that skeletal growth may be programmed during intrauterine or early postnatal life.

(Ann Rheum Dis 1997;56:17-21)
\end{abstract}

MRC Environmental Epidemiology Unit, University of

Southampton,

Southampton General

Hospital,

Southampton, United

Kingdom

C Cooper

C Fall

P Egger

D Barker

Department of Nuclear Medicine, Hertford County Hospital, Hertford, United Kingdom R Hobbs

Clinical Sciences Centre, Northern General Hospital, Sheffield, United

Kingdom

R Eastell

Correspondence to: Dr Cyrus Cooper, MRC Environmental Epidemiology Unit, Southampton General Hospital, Tremona Road, Southampton, SO16 6YD.

Accepted for publication 30 September 1996
Osteoporosis, defined as a reduction in bone mass which predisposes to fracture, constitutes a major public health problem. ${ }^{1}$ Preventive strategies against osteoporotic fractures may be targeted at various stages throughout life, for example, calcium and vitamin D supplementation in the elderly, hormone replacement therapy in the postmenopausal woman, and exercise programmes in childhood. However, a substantial proportion of the variance in bone mass found in the general population cannot be explained by known genetic and environmental determinants. Recent studies of cardiovascular disease have suggested associations with retarded intrauterine and early postnatal growth. ${ }^{2}$ The mechanism underlying these associations is believed to be the programming of a range of metabolic and endocrine systems. Programming is the term used for persisting changes in structure and function caused by environmental stimuli during critical periods of early development. We have recently suggested that growth during prenatal and early postnatal life may be a determinant of peak adult bone mass. ${ }^{3}$ However, the importance of bone mass in young adulthood for fracture risk several decades later is uncertain. We therefore examined the relation between weight gain in infancy and bone mass during the seventh decade of life in a series of men and women born in Hertfordshire during 1920-30.

\section{Methods}

In the county of Hertfordshire, from 1911 onwards, all births were notified by the attending midwife. ${ }^{4}$ Almost all of these births took place at home. The name and address of the baby, the date of birth, and the birth weight were registered. A health visitor saw the baby periodically through its first year and recorded its manner of feeding (whether breast fed or not), and its weight at the age of 1 year. With the help of the National Health Service Central Registry at Southport, and Hertfordshire Family Health Service Association, we traced men who were born during 1920-1930 and women born between 1923-1930, in the six districts of East Hertfordshire, and who still lived there. Because of the change of name on marriage, it is difficult to trace women before 1923 .

Of those who were traced and found to be still living in East Hertfordshire, 370 men and 285 women took part in a study of cardiovascular risk factors, which included measurements of glucose tolerance, serum lipid and plasma clotting factor concentrations, and blood pressure..$^{5-7}$ For the present study we aimed to recruit 200 men and 200 women. The study had $90 \%$ power to detect a difference in bone mineral density of $0.02 \mathrm{~g}$ $\mathrm{cm}^{-2}$ at the hip, and $0.03 \mathrm{~g} \mathrm{~cm}^{-2}$ at the spine between highest and lowest thirds of the distribution of birth weight or weight at 1 year, using the 5\% significance level. As we expected a $30 \%$ drop out rate, we invited all 285 women, and 300 men chosen randomly from the 370 men in the previous study, to participate in this study. A total of 189 women (66\%) and 224 men $(75 \%)$ completed the study. All the study subjects agreed to be interviewed at home by a nurse. She administered a questionnaire which obtained information on socioeconomic status, medical and drug history, cigarette smoking, alcohol consumption, physical activity, and reproductive variables in women. Dietary calcium intake was assessed using a food frequency questionnaire for current intake, which had previously been validated for use in the elderly. ${ }^{8}$ Bone mineral was measured in each subject by dual energy $x$ ray absorptiometry at the lumbar spine and proximal femur using a Hologic QDR 1000 instrument. Two variables were measured for each site: bone mineral content (BMC; expressed as grams of ashed calcium hydroxyapatite) and bone mineral density (BMD; expressed as grams of ashed calcium hydroxyapatite per unit area scanned). Measurement precision, expressed 
Table 1 Distributions of body weight, bone mass, and serum osteocalcin among 224 men and 189 women born in Hertfordshire during 1920-1930

\begin{tabular}{|c|c|c|c|c|}
\hline \multirow[b]{2}{*}{ Variable } & \multicolumn{2}{|l|}{ Men } & \multicolumn{2}{|c|}{ Women } \\
\hline & Mean & $S D$ & Mean & $S D$ \\
\hline Birthweight (g) & 3598 & 607 & 3460 & 532 \\
\hline Weight at one year (g) & 10305 & 1248 & 9629 & 1074 \\
\hline Adult weight $(\mathrm{kg})$ & 79.9 & 11.7 & 68.9 & 11.5 \\
\hline Adult height $(\mathrm{cm})$ & 172.4 & 6.5 & 160.3 & 5.8 \\
\hline Lumbar spine BMC (g) & 75.7 & 16.0 & 53.4 & 12.8 \\
\hline Femoral neck BMC (g) & 5.1 & 0.9 & 3.9 & 0.6 \\
\hline $\begin{array}{l}\text { Lumbar spine BMD } \\
\left(\mathrm{g} \mathrm{cm}^{-2}\right)\end{array}$ & 1.07 & 0.18 & 0.92 & 0.17 \\
\hline $\begin{array}{l}\text { Femoral neck BMD } \\
\qquad\left(\mathrm{g} \mathrm{cm}^{-2}\right)\end{array}$ & 0.81 & 0.13 & 0.71 & 0.10 \\
\hline $\begin{array}{l}\text { Serum osteocalcin } \\
\quad\left(\mu \mathrm{g} \mathrm{litre}^{-1}\right)\end{array}$ & 7.60 & 3.07 & 8.79 & 2.90 \\
\hline
\end{tabular}

as coefficient of variation, was $1.1 \%$ for lumbar spine $\mathrm{BMD}$ and $1.8 \%$ for femoral neck BMD.

A fasting morning blood sample was obtained from all subjects. Serum was separated and stored at $-70^{\circ} \mathrm{C}$. Serum osteocalcin was measured using a radioimmunoassay with antiserum raised to human osteocalcin and using human osteocalcin for tracer and standard (Nichols Institute, San Juan Capistrano, CA, USA). The intra-assay coefficient of variation was $3 \%$; interassay coefficient of variation was $5 \%$ at $4.8 \mathrm{mg} \mathrm{litre}^{-1}$ and the detection limit was $0.3 \mathrm{mg}$ litre $^{-1}$.

A two hour morning urine sample was also obtained, after overnight fasting, in 101 men and 95 women, selected randomly within fifths of the distribution of infant weight. Type I collagen cross linked N-telopeptide was measured using an enzyme linked immunosorbent assay (ELISA)

Table 2 Weight at birth and one year in relation to bone mineral among 224 men and 189 women born in Hertfordshire during 1920-1930

\begin{tabular}{|c|c|c|c|c|c|c|c|}
\hline \multirow[b]{2}{*}{ Sex } & \multirow[b]{2}{*}{ Weight } & \multirow[b]{2}{*}{ Category } & \multirow[b]{2}{*}{ No } & \multicolumn{2}{|c|}{ Lumbar spine } & \multicolumn{2}{|c|}{ Femoral neck } \\
\hline & & & & $B M C(g)$ & $\begin{array}{l}B M D \\
\left(\mathrm{~g} \mathrm{~cm}^{-2}\right)\end{array}$ & $B M C(g)$ & $\begin{array}{l}B M D \\
\left(g^{-2} \mathrm{~cm}^{-2}\right)\end{array}$ \\
\hline \multirow[t]{8}{*}{$\overline{\text { Men }}$} & \multirow[t]{4}{*}{$\begin{array}{l}\text { Birth } \\
(\mathrm{kg})\end{array}$} & $<3.3$ & 64 & $\begin{array}{l}73.5 \\
(14.4)\end{array}$ & $1.06(0.16)$ & $\begin{array}{l}5.00 \\
(0.84)\end{array}$ & $\begin{array}{l}0.81 \\
(0.12)\end{array}$ \\
\hline & & $3.3-3.75$ & 78 & $\begin{array}{l}76.6 \\
(17.4)\end{array}$ & $1.08(0.20)$ & $\begin{array}{l}5.13 \\
(0.86)\end{array}$ & $\begin{array}{l}0.81 \\
(0.12)\end{array}$ \\
\hline & & $>3.75$ & 82 & $\begin{array}{l}76.8 \\
(15.7)\end{array}$ & $1.05(0.18)$ & $\begin{array}{l}5.12 \\
(0.97)\end{array}$ & $\begin{array}{l}0.80 \\
(0.13)\end{array}$ \\
\hline & & & P-trend ${ }^{\star}$ & 0.14 & 0.95 & 0.36 & 0.54 \\
\hline & \multirow[t]{4}{*}{$\begin{array}{l}1 \text { year } \\
(\mathrm{kg})\end{array}$} & $<9.85$ & 74 & $\begin{array}{l}73.0 \\
(16.9)\end{array}$ & $1.06(0.19)$ & $\begin{array}{l}4.97 \\
(0.91)\end{array}$ & $\begin{array}{l}0.81 \\
(0.14)\end{array}$ \\
\hline & & $9.85-10.75$ & 575 & $\begin{array}{l}76.5 \\
(15.5)\end{array}$ & $1.06(0.17)$ & $\begin{array}{l}5.18 \\
(0.95)\end{array}$ & $\begin{array}{l}0.81 \\
(0.12)\end{array}$ \\
\hline & & $>10.75$ & 75 & $\begin{array}{l}77.8 \\
(15.3)\end{array}$ & $1.07(0.18)$ & $\begin{array}{l}5.12 \\
(0.82)\end{array}$ & $\begin{array}{l}0.81 \\
(0.12)\end{array}$ \\
\hline & & & P-trend ${ }^{\star}$ & 0.03 & 0.57 & 0.25 & 0.90 \\
\hline \multirow[t]{8}{*}{ Women } & \multirow[t]{4}{*}{$\begin{array}{l}\text { Birth } \\
(\mathrm{kg})\end{array}$} & $<3.18$ & 66 & $\begin{array}{l}50.7 \\
(12.8)\end{array}$ & $0.89(0.18)$ & $\begin{array}{l}3.78 \\
(0.65)\end{array}$ & $\begin{array}{l}0.70 \\
(0.09)\end{array}$ \\
\hline & & $3.18-3.63$ & 64 & $\begin{array}{l}54.7 \\
(13.6)\end{array}$ & $0.94(0.17)$ & $\begin{array}{l}3.95 \\
(0.67)\end{array}$ & $\begin{array}{l}0.72 \\
(0.11)\end{array}$ \\
\hline & & $>3.63$ & 58 & $\begin{array}{l}55.0 \\
(11.6)\end{array}$ & $0.93(0.16)$ & $\begin{array}{l}3.91 \\
(0.56)\end{array}$ & $\begin{array}{l}0.71 \\
(0.09)\end{array}$ \\
\hline & & & P-trend ${ }^{\star}$ & 0.056 & 0.14 & 0.21 & 0.43 \\
\hline & \multirow[t]{4}{*}{$\begin{array}{l}1 \text { year } \\
(\mathrm{kg})\end{array}$} & $<9.1$ & 66 & $\begin{array}{l}50.5 \\
(12.8)\end{array}$ & $0.90(0.18)$ & $\begin{array}{l}3.75 \\
(0.65)\end{array}$ & $\begin{array}{l}0.70 \\
(0.10)\end{array}$ \\
\hline & & $9.1-10.0$ & 61 & $\begin{array}{l}53.8 \\
(10.2)\end{array}$ & $0.92(0.15)$ & $\begin{array}{l}3.85 \\
(0.56)\end{array}$ & $\begin{array}{l}0.70 \\
(0.09)\end{array}$ \\
\hline & & $>10.0$ & 61 & $\begin{array}{l}56.1 \\
(14.6)\end{array}$ & $0.94(0.19)$ & $\begin{array}{l}4.05 \\
(0.65)\end{array}$ & $\begin{array}{l}0.73 \\
(0.11)\end{array}$ \\
\hline & & & P-trend ${ }^{\star}$ & 0.01 & 0.21 & 0.01 & 0.09 \\
\hline
\end{tabular}

Figures are mean values for bone mineral within each third of the distribution of weight at birth or one year; figures in parentheses are standard deviations.

$\star \chi^{2}$ test for linear trend, after adjusting for age.
(Ostex Inc, Seattle, Washington, USA). ${ }^{9}$ The intra-assay coefficient of variation was $3.8 \%$ and interassay coefficient of variation was $6.2 \%$. Creatinine was quantified in urine samples by the Jaffe procedure and cross link excretion was expressed as a ratio to creatinine excretion.

\section{STATISTICS}

We explored the relation between body weight at various ages and adult BMC and BMD using linear regression, and by categorisation of weight in thirds. Partial correlation coefficients after age adjustment were tested for statistical significance, as were linear trends in the values of bone mineral within thirds of the weight distribution. The influence of potential confounding variables was examined using multiple regression. Variables with a skewed distribution (for example, the collagen cross link/creatinine ratio in urine) were normalised by log transformation.

\section{Results}

The anthropometric and bone mineral measurements of the 413 study subjects are shown in table 1 . The mean values for BMC and $\mathrm{BMD}$ were greater $(\mathrm{P}<0.001)$ in men than in women, although this difference was more pronounced for BMC. The mean values for birth weight, weight at 1 year, adult weight, and adult height were also higher $(\mathrm{P}<0.001)$ among men than women. The mean age of the men was 66.1 (SD 3.2) years and that of the women 65.6 (2.8) years. The mean calcium intake of the sample was 684 (SD 233) $\mathrm{mg} \mathrm{d}^{-1}$, and their median duration of outdoor walking was $72 \mathrm{~min}^{-1}$ (interquartile range, IQR, 45-100 $\left.\mathrm{min}^{-1}\right)$. One hundred and eighty two men $(76 \%)$ and 87 women $(43 \%)$ were previous or current smokers. The median age at menopause of the women was 50 years (IQR 48-53 years), and only six women in the cohort had used hormone replacement therapy.

Table 2 shows the relation between body weight at birth and at 1 year of age, and skeletal status at age $63-73$ years. The table presents the mean values of bone mineral at the lumbar spine and femoral neck, within each third of the distribution of body weight at each age. Among women, there was a weak but statistically significant relation between weight at 1 year and BMC at the spine and hip. There was a similar trend among men, but this only attained statistical significance at the spine. Weight at 1 year was not significantly associated with BMD at either site, nor was birth weight associated with either measure of bone mineral. These findings were not appreciably altered by adjusting for age within the 10 year age range included in the study. The figure illustrates the relation of weight at 1 year and BMC at the spine and hip among men and women. Women in the highest third of the distribution of weight at age 1 year had spine $\mathrm{BMC}$ values $11 \%$ higher than those in the lowest third; the corresponding difference for the femoral neck was $8 \%$.

As expected, the relations between current weight and BMC at the spine and hip (men: spine $r=0.41, \mathrm{P}<0.001$; hip $r=0.48, \mathrm{P}<$ 0.001 , women: spine $r=0.46, \mathrm{P}<0.001$; 
Table 3 Correlations between weights measured at birth and one year with height and weight at age 63-73 years among 224 men and 189 women born in Hertfordshire during 1920-1930

\begin{tabular}{|c|c|c|c|c|}
\hline \multirow{3}{*}{ Sex } & \multicolumn{4}{|c|}{ Anthropometric meeasurements } \\
\hline & \multirow{2}{*}{ Infancy } & \multicolumn{3}{|c|}{ Adulthood } \\
\hline & & Weight & Height & $B M I$ \\
\hline \multirow[t]{2}{*}{ Men } & Birthweight & $0.21 \dagger$ & $0.28 \dagger$ & 0.04 \\
\hline & Weight at one year & $0.30 \dagger$ & $0.41 \dagger$ & 0.10 \\
\hline \multirow[t]{2}{*}{ Women } & Birthweight & $0.11^{\circ}$ & $0.15^{\star}$ & 0.04 \\
\hline & Weight at one year & $0.22 \dagger$ & $0.33 \dagger$ & 0.06 \\
\hline
\end{tabular}

BMI, body mass index.

Figures are correlation coefficients.

$\star \mathrm{P}<0.05 ; \dagger \mathrm{P}<0.001$.

Table 4 Serum osteocalcin, urine collagen cross-link excretion, and bone mineral density among men and women born in Hertfordshire during 1920-1930

\begin{tabular}{lllll}
\hline \multirow{2}{*}{ Marker } & \multirow{2}{*}{ Sex } & No subjects & \multicolumn{2}{l}{ Bone mineral density $\left(\mathrm{g} \mathrm{cm}^{-2}\right)$} \\
\cline { 3 - 5 } & & Lumbar spine & Femoral neck \\
\hline Osteocalcin & Men & 213 & $-0.15^{\star}$ & $-0.19 \dagger$ \\
& Women & 188 & $-0.24 \dagger$ & $-0.27 \dagger$ \\
Log NTX/cr & Men & 101 & -0.19 & $-0.23^{\star}$ \\
& Women & 95 & $-0.43 \ddagger$ & $-0.21^{\star}$ \\
\hline
\end{tabular}

Figures are partial correlation coefficients after age adjustment.

Log NTX/cr, log transformed values of type I collagen cross linked N-telopeptide/creatine. ${ }^{\star} \mathrm{P}<0.05 ;+\mathrm{P}<0.01 ; \ddagger \mathrm{P}<0.001$.

Lumbar spine
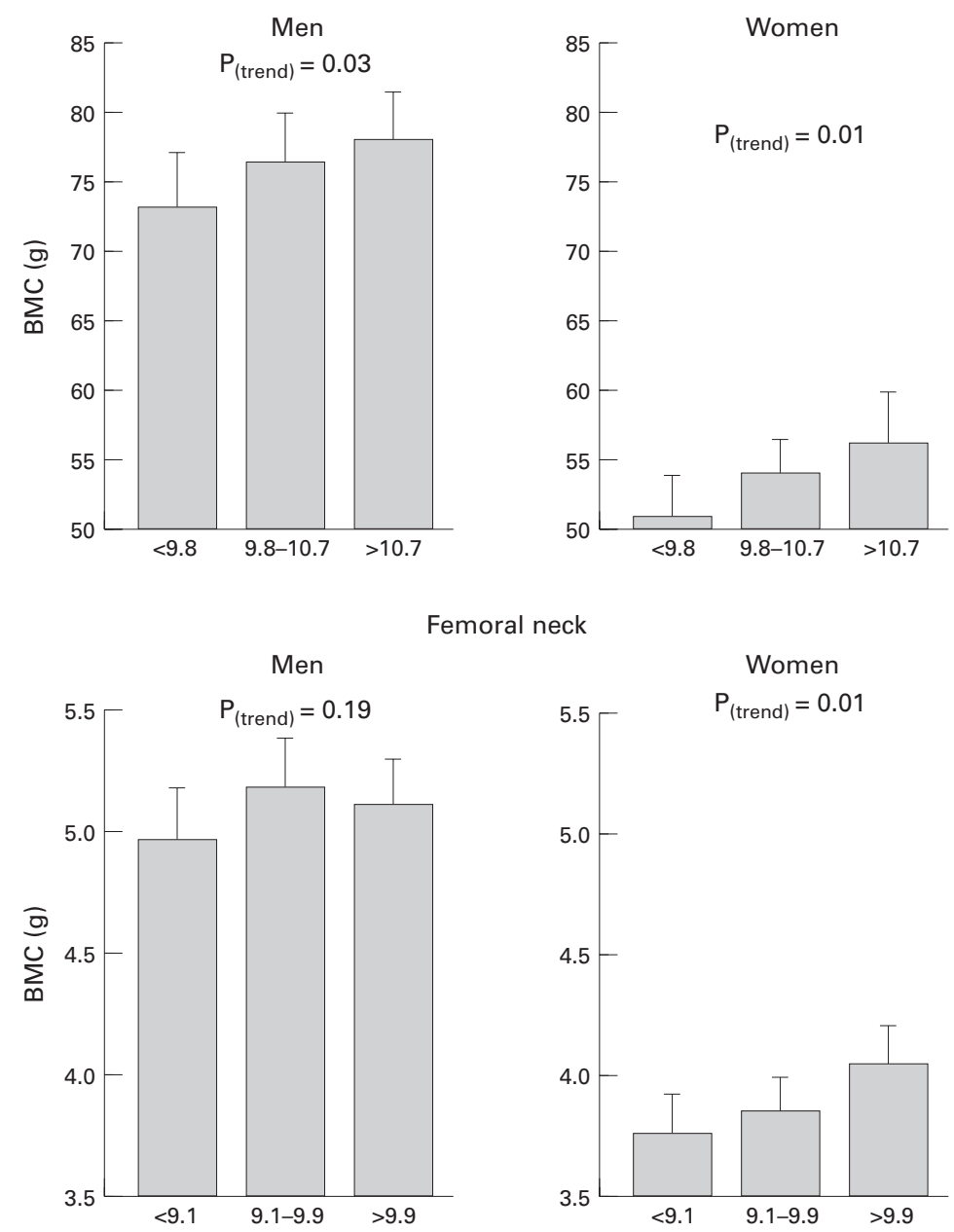

Femoral neck

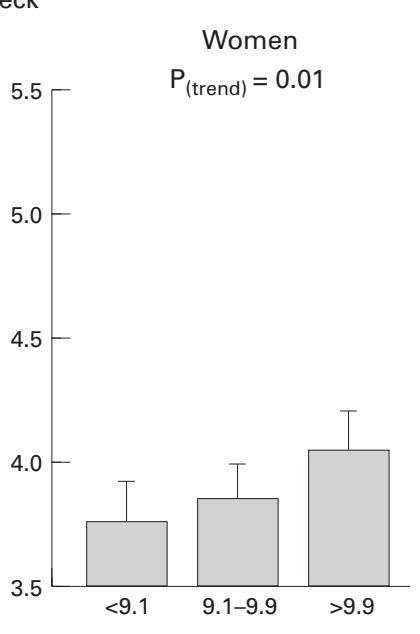

Weight at 1 year $(\mathrm{kg})$

Weight at 1 year and bone mineral content of the lumbar spine (LS-BMC) and femoral neck (FN-BMC) among 224 men and 189 women born in Hertfordshire during 1920-1930. hip $r=0.49, \mathrm{P}<0.001)$ were considerably stronger than those for weight at 1 year (men: spine $r=0.16, \mathrm{P}=0.02$; hip $r=0.06, \mathrm{P}=0.41$, women: spine $r=0.15, \mathrm{P}=0.04$; hip $r=0.15$, $\mathrm{P}=0.03$ ). We therefore explored the relations between birth weight, weight at 1 year, and adult weight, height, and body mass index (table 3). Weight at 1 year was strongly associated with adult height, and less so with adult weight, in both sexes. The associations of adult height and weight with birth weight were less marked, but still significant in men. In contrast, there was no significant association between either infant measure and adult body mass index. When we examined the simultaneous effects of weight at 1 year and adult height on adult spine and hip BMC in a multiple regression model, there was no statistically significant residual effect of weight at 1 year on BMC at either site. However, the effect of weight at 1 year on adult BMC remained significant after adjusting for age, social class, smoking, alcohol consumption, calcium intake, activity level, and years since menopause, in women. Two hundred and ninety four subjects $(71 \%)$ were exclusively breast fed, 19 (5\%) were exclusively bottle fed, and the remaining 99 (24\%) had a mixed feeding pattern. There was no statistically significant relation between the pattern of infant feeding and adult BMC or BMD at either skeletal site. There was also no significant effect of social class at birth on these measures of bone mineral.

Although subjects with a higher current calcium intake tended to have greater BMD at the lumbar spine and femoral neck, these relations did not attain statistical significance for either sex. We attempted to estimate lifetime calcium intake in relation to current intake, but these two variables were highly correlated. Again, we were unable to show a statistically significant relation between lifetime intake and bone density.

We examined the relation between the biochemical markers of bone turnover and each of bone density (table 4) and body build. The values for urinary excretion of the type I collagen cross linked N-telopeptide were skewed, and so were log transformed for theseanalyses. Table 4 shows that there were statistically significant negative associations between both bone turnover markers and BMD among women. Among men, the associations were negative in direction, but somewhat weaker than those found among women. Although both markers showed significant negative associations with current weight, they were not related to birth weight or weight at 1 year. When we adjusted the relations between bone turnover markers and BMD for age and current weight, the associations among women remained statistically significant at both skeletal sites.

\section{Discussion}

We traced the population of men and women born in one part of Hertfordshire during 1920-30 whose weights in infancy were recorded. Weight at 1 year of age was a weak but significant predictor of bone mineral 
content in the lumbar spine and femoral neck of women, and lumbar spine of men, some seven decades later. These relations appear to be specific for bone mineral content, as compared with bone mineral density, at these two sites, and accord with our earlier finding that weight gain in infancy is correlated with bone mineral content in early adulthood. ${ }^{3}$ They suggest that the influence of infant growth on adult skeletal size and mineral content is substantially weaker, but still detectable, during the seventh decade of life - a period when reduced bone mass has been directly linked to the risk of fracture.

Of all singleton boys and girls born in the area during the study period, $61 \%$ were weighed both at birth and at 1 year. Those who were not weighed at these ages may have differed from those who were. However, our analysis was based on internal comparisons, and bias would be introduced only if the relation between infant growth and adult bone mass differed in the two groups; this is unlikely. We traced $75 \%$ of the men and $66 \%$ of the women approached, despite the lapse of more than 60 years. Again, bias from exclusion of those untraced is unlikely because the comparisons were internal. The variation within the data enable us to make comparisons across a wide range of weights and suggests that the observations may be reasonably extrapolated to other populations. Finally, although our sample comprised only a small proportion of all live births in Hertfordshire during the period 1920-30, we have previously shown that the distribution of body mass index and prevalence of cigarette smoking in these men and women are similar to estimates derived from British population samples of comparable age such as the General household survey. ${ }^{10}$

Adult bone mass is a function of both bone size and density. ${ }^{11}$ These two components are likely to be determined by different factors. Growth is the most important determinant of the former, and our results suggest that the growth trajectory is established early in life. Given a certain skeletal size, the mineral density within that bony envelope appears to be modified by a host of locally acting factors such as hormonal status and physical activity, which influence bone modelling and remodelling. Both these variables (bone size and density) influence fracture risk. ${ }^{12-14}$ Fracture risk is also dependent upon the geometry and architecture of particular skeletal sites. At the hip, prospective studies suggest that the length of the hip axis is positively associated with fracture risk, ${ }^{15}$ and that this association is independent of bone density. Growth retardation at critical periods of early development might disproportionately influence hip axis length, and thereby hip fracture risk. Although this variable could not be measured at baseline, it has been included in a follow up study of the same individuals after a four year interval.

The association we observed between weight at 1 year and adult bone mineral content adds to the body of circumstantial evidence that skeletal size tracks from childhood. ${ }^{16}{ }^{17}$ The loss of the effect of weight at 1 year after adjusting for current height, and our finding that infant weight correlated more strongly with adult height than with adult body mass index (a measure of adiposity), support this interpretation. Although our findings are consistent with those of a previous study of young women, the association of infant weight with BMC at age 65 years was substantially weaker (explaining only $2.5 \%$ of the overall variance) than that with BMC at age 21 years. This might reflect greater measurement error in the recording of body weight 70 years ago, or might have a biological basis in the multitude of factors which modify bone mineral content during adulthood.

The emergence of the relation of body weight at 1 year with adult BMC is compatible with previously published data showing no appreciable association between birth weight and adult bone mass. ${ }^{18}$ Body size and composition at birth largely reflect the supply of nutrients and oxygen to the growing fetus. Thus maternal characteristics such as parity, smoking, social class, and height predominate among determinants of birth weight. ${ }^{19}$ The postnatal growth trajectory becomes apparent by the age of 1 year, as evidenced by the substantially better correlations of adult height with weight at 1 year, compared with birth weight.

There are clearly strong genetic contributions to skeletal growth. ${ }^{20}$ However, growth is also amenable to environmental modulation. During fetal and early postnatal life, there are critical periods during which environmental insults, for example malnutrition, might permanently alter subsequent growth trajectory. ${ }^{212}$ The phenomenon whereby an early environmental influence, acting at critical periods of development, has lasting or lifelong significance is known as programming. ${ }^{22}$ One of the best examples of this phenomenon is the lifelong effect of early exposure to sex hormones on sexual physiology. A female rat injected with testosterone propionate on the fifth day following birth develops normally until puberty, but fails to ovulate or show normal patterns of female sexual behaviour thereafter. ${ }^{23}$ Pituitary and ovarian function are normal, but the release of gonadotrophin by the hypothalamus has been irreversibly altered from the cyclical female pattern of release to the tonic male pattern. If the same injection is given at 20 days old, it has no effect. Thus there is a critical time at which the animal's sexual physiology is sensitive and can be permanently changed. Other animal experiments have show that when the protein or energy intake of the mother during pregnancy and lactation is lowered, the offspring are smaller than they would otherwise have been. In general, the earlier in life that undernutrition occurs, the more likely it is to have permanent effects on body weight and length. ${ }^{24}$

Our observation that the association of infant weight with adult bone mineral content disappeared after correction for bone area suggests that environmental factors modify the influence of genetic determinants of skeletal growth throughout life so that the latter are relatively less important in elderly individuals. 
The precise timing and mechanism of programming is unknown. Symmetrical, but slow, postnatal growth is a characteristic of fetal adversity during the third trimester. ${ }^{24} 25$ There are several mechanisms whereby such adversity could compromise the skeleton. These include interactions of an adverse environment with gene expression, the programming of endocrine systems (such as the growth hormone/insulin-like growth factor 1 axis, the hypothalamic/pituitary/gonadal axis or the parathyroid hormone/vitamin D axis), and, finally, the coupling between osteoblast and osteoclast activities. Out data do not support the last of these possibilities. We observed a stronger relation between weight in infancy and adult height among men than among women, although the findings with BMC were more marked among women. This discrepancy might be explained by the differential effects of gonadal steroids and the growth hormone/IGF-1 axis on skeletal growth. Further evidence for the programming of gonadal function in women comes from the observation that birth weight is a significant predictor of menarcheal age after accounting for the effects of childhood body build. ${ }^{26}$

The relation between various biochemical markers of bone turnover and bone mineral density is controversial. Some previous studies have documented a negative association between these markers and bone density ${ }^{27-29}$ but others have not. ${ }^{3031}$ One reason for this inconsistency is the wide age range of subjects included in many of these studies, making it difficult to disentangle confounding by age. Our study included relatively large numbers of elderly men and women, within a relatively narrow age range, and showed significant negative associations, among women, between serum osteocalcin, fasting urine collagen cross link excretion, and bone density. The associations for both markers were weaker among men. However, even in women, the markers only explained $10-15 \%$ of the variance in adult bone density and were not sufficiently predictive of BMD for use in individuals.

In conclusion, this study supports our previous observation that growth in infancy is weakly associated with skeletal size in adulthood. The genetic and environmental programming of the skeletal growth trajectory, and any concomitant adverse effect on age related bone loss, require further study in order that current strategies to prevent osteoporosis may be enhanced.

This study was supported by project grants from the Wessex Medical School Trust and the Medical Research Council of Great Britain. We thank the subjects who participated in the study, and the nurses who performed the interviews and venepuncture. We also thank Hertfordshire County Archives and the Hertfordshire health authorities who preserved the records and allowed us to use them, and the staff at the NHS central registry, Southport, and Office of Population Censuses and Surveys, London, who traced the men and women. The measurements of serum osteocalcin and urine collagen cross links were made by Michelle Naylor and Louise Conyard and computing support was provided by Vanessa Cox and Paul Computing support was provided by Vanessa Cox and Pau
Winter. The manuscript was prepared by Katy Cuninghame.

1 Cooper C. Epidemiology and public health impact of osteoporosis. Baillieres Clin Rheumatol 1993;7:459-77.

2 Barker DJP. Fetal origins of coronary heart disease. BMJ 1995;311:171-4.
3 Cooper C, Cawley M, Bhalla A, Egger P, Ring F, Morton L, et al. Childhood growth, physical activity and peak bone
mass in women. J Bone Miner Res 1995;10:940-7.

4 Barker DJP, Winter PD, Osmond C, Margetts B, Simmonds SJ. Weight in infancy and death from ischaemic heart disease. Lancet 1989;ii:577-80.

5 Barker DJP, Meade TW, Fall CHD, Lee A, Osmond C, Phipps K, et al. Relation of fetal and infant growth to plasma fibrinogen and factor VII concentrations in adult life. BMJ 1992;304:148-52.

6 Hales CN, Barker DJP, Clark PMS, Cox LJ, Fall C, Osmond C, et al. Fetal and infant growth and impaired glucose tolerance at age 64. BMJ 1991;303:1019-22.

7 Fall CHD, Vijayakumar M, Barker DJP, Osmond C, Duggleby $S$. Weight in infancy and prevalence of coronary heart disease in adult life. BMJ 1995;310:17-19.

8 Nelson M, Hague G, Cooper C, Bunker V. Calcium intake in the elderly: validation of a dietary questionnaire. J Hum Nutr Diet 1988;1:115-27.

9 Hanson DA, Weis MAE, Bollen A, Maslar SL, Singer FR, Eyre DR. A specific immunoassay for monitoring human bone resorption: Quantitation of type I collagen crosslinked N-telopeptides in urines. J Bone Miner Res 1992;7: 1251-8.

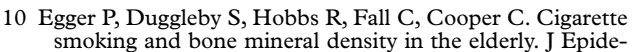
miol Commun Health 1996;50:47-50.

11 Theintz G, Buchs B, Rizzoli R, Shosman D, Clarien H, Sizonenks PC, et al. Longitudinal monitoring of bone mass accumulation in healthy adults: evidence for a marked reduction after 16 years of age at the levels of lumbar spine and femoral neck in female subjects. J Clin Endocrinol Metab 1992;75:1060-5.

12 Carter DR, Bouxsein ML, Marcus R. New approaches for interpreting projected bone densitometry data. J Bone Miner Res 1992;7:137-45.

13 Cummings SR, Marcus R, Palermo L, Ensrud KE, Genant $\mathrm{HK}$, and the Study of Osteoporosis Fractures Research Group. Does estimating volumetric bone density of the femoral neck improve the prediction of hip fracture? A prospective study. J Bone Miner Res 1994;9:1429-32.

14 Gilsanz V, Boeschat MI, Gilsanz R, Loro ML, Roe TF, Goodman WG. Gender differences in vertebral sizes in adults: biomechanical implications. Radiology 1994;190: 678-82.

15 Faulkner KG, McClung M, Cummings SR. Automated evaluation of hip axis length for predicting hip fracture. J Bone Miner Res 1994;9:1065-70.

16 Johnston FE. Somatic growth of the infant and pre-school child. In: Faulkner F, Tanner JM, eds. Human growth: a comprehensive treatise, volume 2. New York: Plenum Press, 1986:3-24

17 Guo SS, Roche AF, Chumlear WC, Gardner JD, Sievervogel RM. The predictive value of childhood body mass index values for overweight at age 35 years. Am J Clin Nutr 1994;59:810-9.

18 Hamed HM, Purdie DW, Ramsden CS, Carmichael B, Steel SA, Howey S. Influence of birthweight on adult bone mineral density. Osteoporosis Int 1993;3:1-2.

19 Goldstein H. Factors related to birthweight and perinatal mortality. Br Med Bull 1981;37:259-64.

20 Morrison NA, Qui JC, Tokita A, Kelly PJ, Crofts L, Nguyen TV, Sambrook PN, Eisman JA. Prediction of bone density from vitamin D receptor alleles. Nature 1994;3 67:284-7.

21 Barker DJP. Programming the baby. In: Barker DJP, ed. Mothers, babies and disease in later life. London: BMJ Publishing Group, 1994:14-36.

22 Lucas A. Programming by early nutrition in man. In: Bock GR, Whelan J, eds. The childhood environment and adult disease. Chichester: John Wiley and Sons, 1991:38-55.

23 Barraclough CA. Production of anovulatory, sterile rats by single injections of testosterone propionate. Endocrinology 1961;68:62-7.

24 Barker DJP, Gluckman KD, Godfrey KM, Harding JE, Owens JA, Robinson JS. Fetal nutrition and cardiovascular disease in adult life. Lancet 1993;341:938-41.

25 Widdowson EM, McCance RA. The effect of finite periods of undernutrition at different ages on the composition and subsequent development of the rat. Proc R Soc Lond 1963;158:329-42.

26 Cooper C, Kuh D, Egger P, Wadsworth M, Barker D. Childhood growth and age at menarche. Br J Obstet Gynaecol 1996;103:814-7.

27 Delmas PD, Stenner D, Wahner H, Mann KG, Riggs BL.Increase in serum bone gamma-carboxyglutamic acid protein with aging in women. J Clin Invest 1983;71:1316-21.

28 Sowers MR, Clark MK, Hollis B, Wallace RB, Jannausch M. Radial bone mineral density in premenopausal and perimenopausal women-a prospective study of rates and risk factors for loss. J Bone Miner Res 1992;7:647-57.

29 Szulc P, Arlot M, Chapuy MC, Duboeuf F, Meunier PJ, Delmas PD. Serum undercarboxylated osteocalcin correlates with hip bone mineral density in elderly women. J Bone Miner Res 1994;9:1591-5.

30 Kelly PJ, Pocock NA, Sambrook PN, Eisman JA. Age and menopause-related changes in indices of bone turnover. $\mathrm{J}$ Clin Endocrinol Metab 1989;69:1160-5.

31 Hansen MA. Assessment of age and risk factors on bone density and bone turnover in healthy premenopausal women. Osteoporosis Int 1994;4:123-8. 